\section{The Blue Flame produced by Common Salt on a Coal Fire.}

Ir is sometimes stated that the blue flame which is seen when common salt is thrown on to a coal fire is due to traces of copper in the coal. It is much more likely that this flame is that of carbon monoxide produced by the cooling of the hot coal by the salt, and certain observations lend support to this view, such as the following :

(I) The blue flame is visible under proper conditions without the addition of salt (and is commonly held to portend frosty weather).

(2) The addition of salt to a fire consisting of whitehot embers - that is, one from which most of the carbon has been burnt-gives no blue flame, which it should do if the flame is due to copper chloride.

(3) The addition of other substances than sodium chloride produces the same effect, a spent filter paper for example.

(4) The colour of the flame seen is apparently identical with that of the carbon monoxide flame but not with the green copper colour.

(5) The sodium flame is never observed in this case because the temperature is too low to volatilise the sodium chloride. For a similar reason it is unlikely that the copper flame can be observed.

Possibly I am wrong, but the matter is interesting, and deserves to be made clear.

63 Goldington Avenue, Bedford.

Mr. Hughes's letter raises some interesting questions regarding the conditions under which the "blue flame" of the coal fire appears. There is no reason to suppose that under appropriate conditions the flame of burning carbon monoxide cannot be seen in a coal fire, but it would be difficult to identify since the spectrum is, in the main, continuous. On the other hand, the blue flame of copper chloride, which is distinct from the green flame of the oxide, has a very characteristic spectrum, and there is no difficulty in its identification. There is no doubt, however, that for the appearance of the spectrum of a compound certain accessory conditions have to be fulfilled, and in many cases their effect is by no means obvious. Perhaps one of the most striking instances of this is to be found in the appearance of the spectrum associated with burning sulphur in the flame of an ordinary bunsen burner when the gases of the flame are cooled, e.g. by holding a thick plate of cold metal in the flame. In this case the sulphur occurs as an impurity in the coal gas but is not seen in the spectrum of the burning gases unless they are cooled.

Winforton House, Hereford. T. R. MERToN.

\section{Pilot Lamps in Laboratories.}

Types of neon vacuum tubes recently placed on the market as low candle-power glow lamps for household electric lighting circuits, apart from other uses, have several convenient applications in laboratories as indicators to show when the supply current is flowing in any given circuit. These lamps, which are said by the makers to give only $\frac{1}{4}$ c.p., have a very high resistance and small current consumption: one type tested on a 200-volt circuit took either 3 or Io milliamperes, according to the polarity of the connections, while another type took I2 and 30 milliamperes under the same conditions, though individual lamps of the same type vary considerably. In each case the lamp behaved well with a resistance of more than $20,000 \mathrm{ohms}$ in series, and a current consumption of less than one milliampere.

In the case of electric furnaces, muffles, etc., one lamp in parallel with the heating winding serves to show when the current is " on," obviating the chance of the apparatus being left under load when the laboratory is closed at night, and effecting obvious economies by indicating the consumption of current at other times. With electrically heated thermostats, incubators, constant temperature ovens, etc., where the means of heating are not directly visible, a neon lamp serves usefully to indicate contact when making adjustments, while the use of a second lamp shunted across the contact breaker reduces arcing and removes any doubt as to the supply of current when the other lamp is out. Fig. I shows a

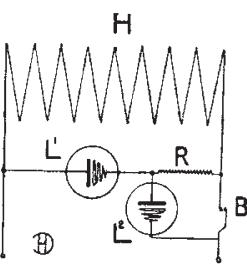

FIG. I. simple method of placing the two lamps in such a circuit. $\mathrm{H}$ is the heater winding, $\mathrm{B}$ the break, $\mathrm{L}^{1}$ and $\mathrm{L}^{2}$ the two neon lamps, while $\mathrm{R}$ is a high resistance of 20,000 ohms or more, made by drawing pencil lines on a piece of ebonite between two terminals until a satisfactory glow is given by the lamps.

The working of such an arrangement is selfexplanatory, one of the two lamps always being alight while the current is on. The current consumption on 200 volts is only $\frac{1}{5}$ th watt-or 5000 hours' service for the cost of one unit.

Where these lamps are required as "pilots" for a large number of circuits, advantage may be taken of the special types designed for advertising purposes, where the electrodes are given the form of letters and other symbols. The makers are prepared to manufacture these in any form if necessary, and such simple words as "on " and "off" could be provided if required. For details of other uses of these interesting lamps reference may be made to a communication in NATURE, March I6, p. 343.

Botanical Laboratory, Shirley Institute, H. J. DENHAM. Didsbury, May 8.

\section{The Speckled Wave Front of Light.}

IN view of Sir J. J. Thomson's suggestion (quoted by Reiche, "Quantentheorie," p. 25) that the wave front of light may have a speckled structure, it may be asked whether anything peculiar happens when two specks, belonging to different waves, collide. They might, for example, be deviated from their courses. If so, one light wave would cause some scattering of another wave with which it collided, and the direct light in the second wave would be dimmed. This effect, if it exists at all, must be small or it would have been noticed. Evidence as to its existence might be obtained in the following way. The supposed dimming of the second ray would be likely to depend on the angle between it and the first ray. On this supposition the brightness of a star lying on the ecliptic would vary slightly with the angle between it and the sun, as seen from the earth. Russell (Astrophys. Journ., vol. xliii., I916) has shown that the brightness of the moon does so vary, but that has been explained otherwise.

On the Maxwellian view of light the reduction of observations which is here suggested appears so meaningless that it has possibly never been tried.

LEwIS F. RichaRdSON.

Westminster Training College, S.W.r.

NO. 2743, VOL. IOg] 